\title{
SABERES Y PRÁCTICAS PESQUERO-ARTESANALES: COTIDIANEIDADES Y DESARROLLO EN LAS CALETAS DE GUABÚN Y PUÑIHUIL, ISLA DE CHILOÉ ${ }^{1}$
}

\author{
ARTISANAL FISHING KNOWLEDGE AND PRACTICES: QUOTIDIAN EVENTS \\ AND THE DEVELOPMENT OF GUABÚN AND PUÑIHUIL FISHING VILLAGES, \\ CHILOÉ ISLAND
}

\author{
Claudio Gajardo Cortés ${ }^{1}$ y Francisco Ther Ríos ${ }^{2}$
}

\begin{abstract}
El artículo describe el sistema de saberes y prácticas pesquero-artesanales presentes en dos asentamientos de pescadores ubicados en el borde occidental de la Isla Grande de Chiloé, Chile. Además de ser desconocidos por la institucionalidad, estos saberes y prácticas pesquero-artesanales han sido impactados por los cambios regulatorios y técnicos ocurridos principalmente entre los años 1980 y 2000. Sostenemos que la complejidad de prácticas y tiempos, usos y saberes, siempre vinculados a la biodiversidad, implica apropiaciones socioculturales diferenciadas sobre el litoral, lo que en su conjunto es un potencial para el desarrollo y mejor calidad de vida de sus habitantes. Las apropiaciones diferenciadas derivan de procesos territoriales que han originado relaciones específicas entre cada sociedad litoral y sus modos de vida, los recursos costeros próximos y el uso y administración de ellos. La descripción y comparación de estos sistemas son pertinentes para lograr un conocimiento antropolítico que ayuda a dilucidar mejoras en las estrategias de desarrollo territorial con pertinencia cultural, ambiental y económica. El análisis de los saberes y prácticas pesqueroartesanales permite así orientar dichas estrategias, diseñando desde sus características particulares alternativas y posibilidades que permiten a las comunidades de pescadores artesanales hacer frente a la inminente crisis de recursos del mar.

Palabras claves: saberes y prácticas pesquero-artesanales, apropiación sociocultural del litoral de Chiloé, antropolítica del desarrollo litoral, Isla Grande de Chiloé.
\end{abstract}

The article describes the system of knowledge and practice of artisanal fishing present in two fishing settlements located on the western edge of the Isla Grande de Chiloé, Chile. Besides being unknown institutionly, this knowledge and artisanal fishing practices have been impacted by regulatory and technical changes that occurred mainly between 1980 and 2000. We argue that the complexity of practice and time, uses and knowledge, always linked to biodiversity, involves differentiated sociocultural appropriation on the coast, which as a whole has potential for development and improved quality of life of its inhabitants. The differentiated appropriations derive from territorial processes that have caused specific relationships between each littoral society and it ways of life, nearby coastal resources and the use and management of them. The description and comparison of these systems are relevant to achieving a political - anthropological knowledge that helps elucidate improvements in culturally, environmentally and economically appropriate territorial development strategies. The analysis of artisanal fishing knowledge and practices thus allows and orients such strategies designed from its special, alternative features and possibilities that permit artisanal fishing communities to face the imminent crisis of marine resources.

Key words: Knowledge and practices of artisanal fishing; sociocultural appropriation of the coast of Chiloé, anthropolitical policy of coastal development Isla Grande de Chiloé.

La pesca artesanal, aunque produce el $60 \%$ de la captura de peces marinos en el mundo, ha sido marginada por las políticas de gobierno que tienden a favorecer la pesquería a gran escala para el comercio (Berkes 2008:443). Esta invisibilidad de los pescadores artesanales en la elaboración de políticas pesqueras (Alcalá 1999, 2003; Baliero et al. 2006) deriva en regulaciones con escasa efectividad
(Bitrán 1989) y falta de alternativas de manejo (FAO 2006). En este contexto, la investigación de los saberes y prácticas pesquero-artesanales, en vistas a evidenciar posibles estrategias de desarrollo territorial y manejo local de recursos, resulta fundamental para repensar alternativas en el mundo de la pesca artesanal (Freire 2001) y contribuir a la sostenibilidad ambiental de las pesquerías.

\footnotetext{
1 Programa de Magíster en Ciencias Sociales, Centro de Estudios del Desarrollo Local y Regional, Universidad de Los Lagos, Osorno, Chile. cegajardo@ hotmail.com

2 Centro de Estudios del Desarrollo Local y Regional, Universidad de Los Lagos. Dirección Postal: Calle Lord Cochrane 1056, Osorno, Chile. fther@ulagos.cl
} 
Los saberes y prácticas pesquero-artesanales han sido abordados, en términos de conocimiento ecológico local o tradicional ${ }^{2}$ en asentamientos costeros, principalmente desde las perspectivas de la etnoecología (García-Reyes y Martí-Sanz 2007) y los sistemas socioecológicos (Berkes 2008). Estudios aplicados han establecido relaciones entre el conocimiento de los pescadores y los entornos marinos (Ross y Banuchi 2007), así también se ha enfatizado en los factores que inciden en sus transformaciones (Andriguetto-Filho 1999), los procesos de aprendizaje y adaptación como productores de resiliencia en las comunidades (Berkes y Folke 1997; Berkes y Turner 2005), su importancia para la conservación de recursos en áreas protegidas (Berkes 2004; Diegues 2005), así como también sus modos de integración en sistemas de evaluación ambiental (Johannes 1993), gestión de pesquerías (García-Allut 1999, 2003) y procesos de manejo local de recursos (Berkes 2008).

En la perspectiva de la Antropología del Territorio, la dimensión de los saberes y prácticas pesquero-artesanales corresponde al quehacer socioproductivo inseparable de los modos de vivir y habitar territorios específicos. Desde la cultura local, los habitantes se apropian de la biodiversidad y la geografía de cada asentamiento, al tiempo que impregnan cotidianamente sus costumbres, memorias y afectividades, generando en ellos lo que se denomina territorios vividos (Ther Ríos 2008:68). La comprensión de las culturas de los pescadores artesanales y la integración de sus saberes y prácticas en procesos de desarrollo han sido recomendados por la FAO (McGoodwin 2002) y apoyado por estudios que han demostrado su centralidad para la mantención de la biodiversidad en los ecosistemas marinos (García-Allut 2003), el manejo integrado de zonas costeras (Rebouças et al. 2006), el enriquecimiento del conocimiento sobre el litoral (Morán-Angulo et al. 2010) y el comanejo de recursos costeros (Carlsson y Berkes 2005; Pomeroy y Berkes 1997).

En el litoral chileno, la modernización de la pesca artesanal generó transformaciones en los saberes y prácticas de las comunidades. Hacia 1980, el régimen de libre acceso, concordante al modelo neoliberal, dio como resultado una sobreexplotación de especies (Camus y Hajek 1998; Zuleta 1990) que tuvo negativos impactos sociales, ecológicos (Morales 1986) y económicos. A partir de ello, se impulsaron procesos migratorios y situaciones de nomadismo de pescadores del norte del país que migraron hacia la zona sur de Chile en busca de mejores capturas ${ }^{3}$ (Cereceda 2000; Marín 2007). En el decenio siguiente, el establecimiento de la Ley General de Pesca y Acuicultura (1992) y la implementación de Áreas de Manejo y Explotación de Recursos Bentónicos (AMERB) (1995), acarrearon conflictos y reorientaciones en las prácticas de desplazamiento en el mar, uso de herramientas y organización laboral de los pescadores artesanales.

Actualmente, en el espacio costero la diversidad de actividades y usos, y la coexistencia no armónica de diferentes representaciones culturales (Egaña 2008) intensifican la ocurrencia de conflictos territoriales (Andrade et al. 2008). Dichos conflictos generan que las actividades tradicionales de pesca artesanal, agricultura y ganadería disminuyan frente a nuevas actividades de turismo, acuicultura, pesca industrial y agricultura intensiva (Castro y Alvarado 2009). En las AMERB, los problemas de acceso, competencia por recursos y los robos (Avalos 2006) ponen en cuestión la transformación de los saberes y prácticas en formas de cultivo marino (Vargas 2005). De esta manera, el litoral se presenta con escaso desarrollo tanto en el manejo de recursos como en su ordenamiento territorial, lo cual demuestra la necesidad de integrar ambos campos ${ }^{4}$ en función de estrategias de desarrollo para el sector pesquero artesanal (Barragán et al. 2005; Calfucura y Figueroa 2005).

\section{Área de Estudio}

La isla de Chiloé pertenece a la Región de Los Lagos ${ }^{5}$ y se ubica entre los paralelos $41^{\circ} 50^{\prime}$ y $43^{\circ} 20^{\prime}$ Sur y los meridianos $73^{\circ} 25^{\prime}$ y $74^{\circ} 20^{\prime}$ longitud oeste. Su temperatura media anual es de $10,9{ }^{\circ} \mathrm{C}$. Su borde oriental deslinda en el mar interior, cuyas aguas tranquilas son resguardadas de los vientos oceánicos por un levantamiento de la Cordillera de la Costa, que tras sumergirse en el Canal de Chacao recorre el borde de la isla donde se conoce como Cordillera de Pirulil en el norte y Cordillera de Piuchén hacia el sur (Cox 2007). En contraste con la zona de mar interior, las comunidades consideradas en esta investigación habitan el borde occidental de la isla. Éste constituye un sector de $250 \mathrm{~km}$ de costas, con estrechas planicies litorales (Ceballos 2009) expuestas al oleaje y a los vientos norte (invierno) y sur (verano) provenientes del Oeste. Las colinas son de suaves pendientes 
(Sáez 2006) y proporcionan terrazas de suelos orgánicos (Donoso et al. en Quintanilla 2004) y alturas diversas con máximo en los $800 \mathrm{~m}$ en la Cordillera de Piuchén. Sus playas son pequeñas y están intercaladas por sectores de rocas aptos para la vida de algas, moluscos y vegetación diversa. Por su exposición directa al Océano Pacífico, la influencia de vientos que oscilan entre los 14 y $20 \mathrm{~km} / \mathrm{h}$ (Artal et al. 2009) generan un fuerte oleaje que impulsa elevadas cantidades de algas hacia las playas. A $180 \mathrm{~km}$ mar adentro (Schneider et al. 2007) la rama costera de la corriente de Humboldt, también llamada corriente de los fiordos, alcanza las costas en los $42^{\circ} \mathrm{S}$ (Camus 2001; Fariña et al. 2008), constituyendo un nicho de alimentación para diversas especies marítimas.

En estos ambientes habitan algas tales como huiro (Macrocystis pyrifera) y huiro negro (Lessonia nigrescens) (Jaramillo et al. 2006), luga roja (Gigartina skottsbergii), cochayuyo (Durvillaea antarctica), luche (Porphyra columbina) y pelillo (Gracilaria spp.). Las especies bentónicas más comunes son loco (Concholepas concholepas), erizo de mar (loxechinus albus), machas (Mesodesma donacium), piure (Pyura chilensis) y lapa (Fissurella spp.). Peces tales como mantarraya (Manta birostris), corvina (Cilus gilberti), dos especies de merluza (Merluccius sp. y Macrouronus sp.), entre otras. La rama costera de la corriente de Humboldt proporciona, frente a la costa, una amplia zona de alimentación para la ballena azul (Hucke-Gaete 2004) que además beneficia a otras especies tales como la ballena jorobada (Megaptera noraenglice), orca (Orcinus orca), cachalote común (Physeten catadon), nutria de mar (Lutra felina), lobo marino de dos pelos (Artocephalus australis) y toninas (Cephalorhynchus sp). En los sectores de pastizales, matorrales y bosque nativo junto a pequeños ríos, se constituye un nicho donde habitan entre otros, el pudú ( $P u d u$ pudu) y el zorro chilote o de Darwin (Pseudalopex fulvipes).

Las caletas de Guabún y Puñihuil pertenecen a la Comuna de Ancud, la cual en su conjunto tiene una población de 41.960 personas $^{6}$. En esta Comuna se encuentra la mayor cantidad de pescadores inscritos en la Región de Los Lagos con un total de 3.717 y 94 organizaciones (Valderrama 2009) y 34 caletas decretadas. La población rural representa un tercio de la Comuna y tiende a decrecer respecto a la población urbana, mientras que la población joven (15-29 años) decrece en función de migraciones en busca de mejores oportunidades. Las ocupaciones principales son la pesca $(18,1 \%)$, el comercio $(15,8 \%)$ y la industria $(12,5 \%)$, mientras que la agricultura que representaba el primer lugar en 1992, pasó a ocupar el cuarto lugar hacia 2002. Los desembarques están constituidos por algas $(64,1 \%)$, pescados $(16,3 \%)$, mariscos $(15,5 \%)$, crustáceos $(1,1 \%)$ y otros (Ceballos 2009)

\section{Materiales y Métodos}

La investigación, de carácter cualitativo y no experimental, siguió los lineamientos metodológicos del proyecto FONDECYT 1080665. Los pasos fueron los siguientes: (1) Se seleccionaron dos caletas artesanales derivadas de la muestra del Proyecto; (2) Se estableció una estrategia de análisis según la bibliografía precedente; (3) Se realizaron algunas visitas exploratorias y se discutieron las categorías a utilizar, según los fenómenos identificados y los objetivos de investigación; (4) Se realizó un primer trabajo de campo de carácter etnográfico con estadía en el lugar, siguiendo la orientación temática de las categorías seleccionadas; (5) Se llevó a cabo un segundo trabajo de campo de carácter etnográfico con estadía en el lugar, profundizando en los fenómenos que emergieron en las primeras visitas; (6) Sistematización y análisis de los datos. En la investigación se aplicó una estrategia comparativa, debido a que las dos comunidades hacen uso de la misma figura de administración pesquera. En cada caleta, el AMERB se destina principalmente a la extracción del recurso loco (Concholepas concholepas), sin embargo, cada caleta es portadora de prácticas y saberes diferentes. Mientras que una es habitada por pescadores con origen chilote, la otra está conformada por pescadores venidos desde el norte del país, reconocidamente no chilotes. Esta similitud en las figuras administrativas y diferenciación en el origen de poblamiento permitieron establecer como eje de análisis la pregunta acerca de cómo es que saberes y prácticas con distinto origen territorial hacen uso de un mismo tipo de figura administrativa. En este sentido, la constante en la figura de administración permitiría esclarecer las diferencias entre las prácticas de ambos asentamientos.

Las primeras visitas exploratorias a Guabún y Puñihuil se realizaron en el marco de sesiones de trabajo de campo del Proyecto mencionado, las que se apoyaron en la aplicación piloto de una 
encuesta bioeconómica aplicada por tres geógrafos del equipo de trabajo. A partir de esta aproximación se distinguieron los tipos de prácticas que había en cada caleta y los tipos de apropiación sociocultural. Posteriormente, se realizaron otras dos visitas a terreno con el objetivo de realizar cartografías participativas. Las etnografías se apoyaron también en el concepto de sistema de prácticas (Floriani 2007). Las técnicas consistieron en observaciones sistemáticas de los usos del espacio y las prácticas productivas. Por su parte, las entrevistas en profundidad tuvieron el sentido de conocer la historia local. En el trabajo de campo se realizaron dos terrenos en cada caleta. Las primeras fueron aproximaciones al contexto de las prácticas y saberes, mientras que la segunda estuvo enfocada a profundizar en las prácticas y los saberes pesquero-artesanales de manera separada y específica. La pauta de orientación consistió en las características de los recursos identificados, las técnicas para su extracción y los tiempos del año calendario en que esas prácticas se realizaban en los distintos lugares. También se realizó un viaje a Los Vilos (IV Región) para conocer los puntos de vista acerca de la migración de pescadores hacia Chiloé, donde se realizaron entrevistas con pescadores de mayor edad para conocer tanto las motivaciones como el periodo de emigración hacia otras regiones del país. Luego se realizó una segunda estadía en la caleta de Puñihuil a objeto de profundizar en las actividades productivas desarrolladas por los pescadores que fueron: (1) turismo; (2) pesquerías; (3) buceo; (4) actividades agrícolas. Posteriormente se mantuvieron las visitas a terreno para realizar entrevistas respecto a: historia del lugar e hitos principales, primeros habitantes, variedad de recursos que se extraen en el lugar y actividades productivas asociadas, técnicas de buceo y recolección de orilla. La interpretación de los datos se realizó considerando una matriz de doble entrada que hemos denominado "apropiación sociocultural de la naturaleza en asentamientos de pescadores". Dicho procedimiento permitió elucidar, caracterizar y comparar la diversidad social existente dentro y entre los territorios costeros investigados.

\section{Resultados}

\section{Guabún: Rupturas y Continuidades en una Caleta Agricultora-Mariscadora}

Actualmente, en este territorio existe un sistema de prácticas cuyas actividades se extienden y diversifican por los ambientes de tierra y mar. Sin embargo, al internarse en el mar los habitantes aún no han incorporado actividades de pesca con redes o espineles. Los primeros habitantes de este asentamiento fueron chilotes que tras solicitar tierras fiscales como ocupantes desarrollaron un laborioso proceso de poblamiento y familiarización con actividades de agricultura y pesca para consumo. En sus inicios, la minga fue el articulador social de la comunidad, mediante ella los habitantes pudieron construir una red de comercio e intercambio local. Los tiempos productivos, marcados por la luz solar, intermediaban espacios del hogar, de las cosechas de papas y trigo, de las playas y de los viajes de comercio local. Los agricultores construían chalupas con las cuales, y producto de la abundancia de especies, era posible pescar con redes sin salir mar adentro. La recolección de mariscos era igualmente abundante por la superficie rocosa y no necesitaba del buceo. Los pescados y mariscos se vendían en los alrededores, mientras que para lo demás, se viajaba a caballo hasta Ancud por caminos angostos entre los cerros, llevando los productos en alforjas de lana de oveja tejidas en telar.

En estos saberes y prácticas, las determinaciones ambientales guían el orden de la vida social, pero a su vez, sobre ellas también se impone la voluntad que permite hacer el territorio habitable. De este diálogo resulta una huella hasta el presente. La actitud tranquila, casi contemplativa del habitante de Guabún, que "aunque coquetea con la modernidad, no se la traga" ${ }^{\circ}$, tiene su razón de ser en este imaginario campesino, cuya continuidad hasta el presente se verifica en las prácticas que aún se realizan en tierra. En efecto, aunque desde el principio los habitantes combinaban prácticas de campo y mar, sin embargo, el habitante de Guabún, en pleno conocimiento de su doble carácter socioproductivo, considera un origen campesino y no pescador. Y es por dicha consideración que un segundo hito importante en la memoria de Guabún lo define la llegada de buzos a sus costas que venían en busca del loco (Concholepas concholepas). Para los habitantes de Guabún la pesca incipiente y complementaria a la actividad agrícola no otorgó la identidad de pescador. Fue más bien la actividad del buceo que otorgó ese carácter; dicha actividad está especializada e implica conocer una serie de técnicas e instrumentos. En buena medida, la llegada de cientos de buzos durante la fiebre del loco fue para el habitante de Guabún un verdadero contacto 
con la otredad. Éstos llegaron primero desde la ciudad de Ancud y aproximadamente a partir del año 1975, de otras partes por mar y tierra. En este período llegaron dos personas a vivir a estos sectores, que poco a poco fueron tomando relevancia en los asuntos hasta convertirse en los actuales presidente y tesorero del Sindicato9 ${ }^{9}$. Como los habitantes de Guabún aún derivaban su imagen de la cotidianiedad campesina inicial, la apropiación de los recursos del fondo marino no estaba en juego inmediatamente entre quienes se entienden como campesinos y los buzos recién llegados. "Yo les daba permiso aquí en el campo mío, hacían unos ranchitos provisorios y ahí trabajaban"10. En un comienzo los habitantes de Guabún trabajaron como ayudantes, este es el momento cuando aprenden nuevas técnicas de extracción, al mismo tiempo que dimensionan las enormes ganancias extraídas frente a ellos, durante el período denominado "fiebre del loco"11. Los bueyes para trabajar la tierra se convirtieron en el medio para mover los sacos de locos (Concholepas concholepas) extraídos desde las playas hacia los medios de transporte de los comerciantes. "En el asunto del loco, no fui marino ni buzo, pero trabajaba en tierra, porque ayudaba con los bueyes a varar y a tirar su mercadería y casi ganaba como un buzo porque ganaba bien"12. Lo que se produjo en el fondo fue un irreversible proceso de aprendizaje y cambio cultural, donde el habitante de Guabún comenzó a dejar de aferrarse a la sola imagen de campesino.

Es que uno aprendió con gente del norte, claro, yo por lo menos aprendí, es decir, ellos me enseñaban, me decían, de tal forma, no lo tires tan rápido, pasa esto, pasa lo otro, por eso le digo que ellos eran más experimentados; aquí habían equipos pero lo que más se utilizaba era el profundímetro para saber la profundidad y de ahí era, digamos, conocimiento que se iba traspasando de generación en generación, por ejemplo a mí me decían nunca subas antes que la burbuja grande, si subiste antes que eso, sonaste, hay que ir con la más chiquitita y la más chiquitita va al último, con esa hay que subir ${ }^{13}$.

Este paso de campesino a pescador se produjo a partir de un cruce de saberes entre el buzo venido desde el norte y el habitante de Guabún. Los aprendizajes fueron fundamentales para redefinir la identidad de Guabún y el buen uso que hoy en día hacen de su AMERB. A partir de su experiencia y contacto con el buzo del norte el habitante de Guabún comenzó a percibirse también como hombre de mar. La nueva identificación no sólo emerge de los aprendizajes sino que incluye la observación de que los pescadores del norte eran a fin de cuentas depredadores y terminarían por acabar con los recursos del lugar impidiendo que la nueva generación en Guabún herede dicho beneficio. Junto con la nueva identificación también se produce un distanciamiento y el habitante de Guabún comienza a defender los recursos frente al depredador nortino. En un intento con claro sentido defensivo, Pedro Pino, un lugareño recién llegado a la localidad, forma parte de un Sindicato durante el "boom del pelillo"14 $\mathrm{y}$, posteriormente, en contacto con un funcionario público, se informa de la posibilidad de administrar un sector del mar. Con ello en vista recorre a caballo los hogares de los habitantes de Guabún, que a esa altura ya articulaban perfectamente las actividades campesinas y el buceo. La información entregada por Pedro Pino no genera credibilidad entre los habitantes de mayor edad. "Nadie creía, porque ellos decían -adónde la vio don Pedro que nos van a dar un pedazo de mar-porque claro, ellos creían que el mar era de todos"15. Sólo los más jóvenes apoyaron a don Pedro en la creación del Sindicato. Entre ellos estaba don Claudio Vargas quien, llegado desde Puerto Octay, comenzó a asumir labores de comercialización de los productos y tesorería de las recaudaciones. En él se reflejaría una creciente idea de expandir la producción y obtener mejor provecho de los recursos. Un imaginario del nuevo pescador se estaba forjando, cuyas prácticas de sociabilidad con el exterior y de vida urbana se confrontan en la actualidad con el permanente imaginario campesino, que mantiene su contemplación frente a los cambios. En la actualidad, ambos imaginarios litorales son parte del AMERB del Sindicato de Pescadores y Buzos Algueros los Chonos de Guabún.

En el momento actual la organización formada para el AMERB se mantiene estable; han surgido también nuevas necesidades, como la de desarrollar nuevas organizaciones basadas en figuras de administración pesquero-artesanal que permitan hacerse cargo de nuevos espacios, aún no administrados oficialmente por los actuales miembros del Sindicato. Los habitantes de Guabún han desarrollado un sentido de ir más allá del AMERB, y defender el 
territorio y sus recursos. Los pescadores de Guabún consideran que si los pescadores del norte saben pescar con redes y espineles, ello les está permitiendo aplicar su mentalidad depredadora en el mar frente a las costas de Guabún, lo que les significa un proceso que debe revertirse para asegurar los recursos a las generaciones futuras. Los habitantes de Guabún desean aprender a pescar para administrar los espacios de mar adentro que están frente a su caleta; esta acción -estiman- protegería los recursos pesquero-artesanales que hoy son explotados por embarcaciones de sindicatos de otras localidades. Para eso deberán agregar a su sistema de prácticas un nuevo conjunto de técnicas y conocimientos respecto de la pesca con redes o espineles ${ }^{16}$.

En concreto, y desde el inicio, entre los habitantes de Guabún se evidencia la existencia de una disposición a explorar y adquirir aprendizajes que permitan una apropiación y garantice seguridad a la comunidad, específicamente para la permanencia de las nuevas generaciones en el territorio. Paradójicamente, dicha permanencia en la apropiación ha sido fortalecida por medio del contacto con el pescador nortino, en cuyo proceso no sólo se ha gestado el aprendizaje de técnicas de buceo sino también un sentido de diferenciación respecto a una actitud depredadora que a los ojos de Guabún, motivó la llegada de los pescadores desde el norte. En síntesis, la actitud de defensa de los recursos que manifiestan los habitantes de Guabún en la actualidad ha sido una incorporación de experiencias sobre un imaginario primariamente campesino, que a partir de nuevos contactos, se proyecta en nuevas y variadas apropiaciones del territorio litoral.

\section{Puñihuil: Rupturas y Continuidades en una Caleta Turística-Pesquera y Mariscadora}

Por su difícil acceso, Puñihuil ha sido desde el inicio un territorio habitado esporádicamente por chilotes, quienes realizaron algunas labores de recolección en el lugar. Su poblamiento y posterior uso de los recursos comienza durante el período de la fiebre del loco. La caleta de Puñihuil es un territorio inicialmente habitado por pescadores del norte del país que al observar sus condiciones decidieron hacer uso de sus recursos hasta la actualidad. Puesto que no realizan actividades de agricultura, el sistema de prácticas en este asentamiento se distribuye entre el sector de la playa y el mar. En la playa se ubican las actividades de turismo culinario, realizadas en tres restaurantes principalmente en verano, mientras que en el mar se realizan actividades de pesca con redes, además del buceo y el turismo. Principalmente, esta última actividad se realiza en tres islotes ubicados frente a la playa (Figura 1) a los cuales durante los meses de noviembre a marzo llegan pingüinos de Magallanes y de Humboldt (Spheniscus humboldti) a anidar.

Los primeros pescadores de Puñihuil llegaron al lugar realizando un viaje desde la ciudad de Los Vilos, Región de Coquimbo. Se detuvieron en sectores como Pucatrihue y algunos llegaron a Chiloé, mientras otros siguieron hasta Puerto Natales y Puerto Edén, constituyendo las denominadas ciudades de plástico. Los pescadores de Los Vilos se han caracterizado por sus viajes desde el norte.

En el ' 85 se produjo una migración hacia el sur, pero en años anteriores también hubo migración hacia el norte. Los viejos se iban en bote y los camiones por arriba llevando el equipamiento para hacer las casuchas ${ }^{17}$.

Claramente, el interés de quedarse en Puñihuil radica en la disponibilidad de recursos pesqueroartesanales que ofrecía el lugar. Se dieron situaciones de comercio ilegal y tráfico, que decreció a medida que la cantidad de recursos disminuyó. Luego de ocho años de vida nómada, los pescadores de Los Vilos se asentaron en la ciudad de Ancud y desde allí comenzaron a viajar todos los veranos a trabajar en la caleta Puñihuil.

El sistema de prácticas de este asentamiento se constituyó en primer lugar como sistema asociado sólo a la actividad de buceo. Posteriormente, los buzos de Los Vilos y algunos chilotes que aprendieron a bucear se quedaron viajando esporádicamente hacia la caleta y fue allí cuando comenzaron a descubrir las posibilidades de turismo que brindaban los tres islotes ubicados frente a la playa. Turistas extranjeros fueron los primeros enterados de las comunidades de pingüinos y comenzaron a demostrar a los pescadores la existencia de demanda turística. Las prácticas de turismo consistían en un traslado en bote hacia los islotes en donde se podía observar de cerca las comunidades de pingüinos.

Yo antes trabajaba en turismo (...) nosotros antes, sin permiso sin nada, bajábamos a 

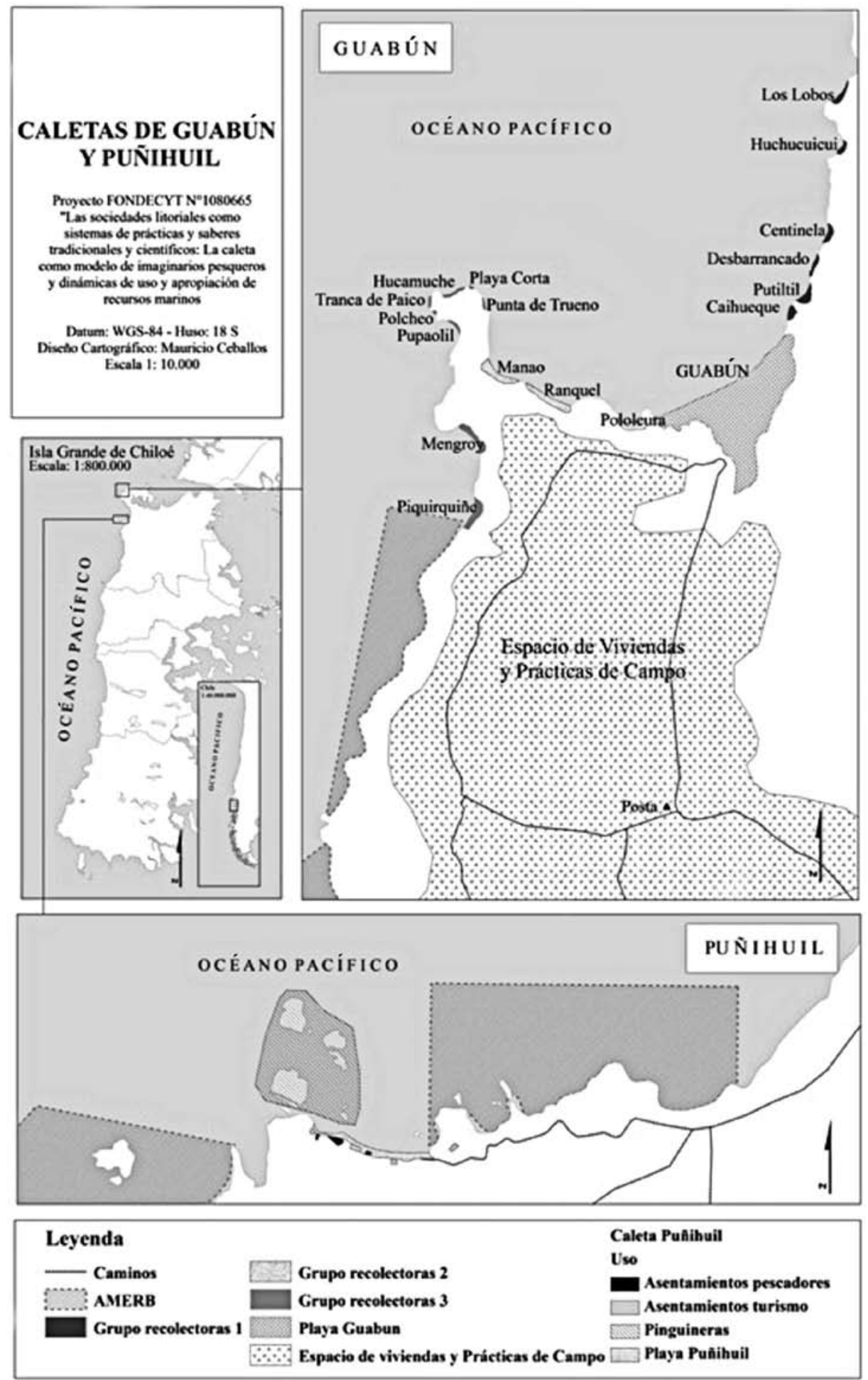

Figura 1. Área de Estudio. Cartografía de apropiación de recursos y prácticas productivas de las caletas Guabún y Puñihuil en Chiloé, Región de Los Lagos.

Area of Study. Cartography of appropriation of resources and productive practices in the fishing villages of Guabún and Puñihuil, in Chiloé, Region de Los Lagos. 
la isla con los turistas, bajábamos porque no teníamos idea, ellos decían que venían a ver los pingüinos porque no sé quien les dijo que aquí habían pingüinos, pero no llegaba tanta gente, llegaban tres, cuatro personas, ibas en el bote y los dejabas ahí en la isla un rato...pero en ese tiempo uno estaba cometiendo un delito, era como matar a los pingüinos, porque le entorpecían el hábitat ${ }^{18}$.

En 1999 fueron declarados monumento natural los islotes de Puñihuil. En tanto la fundación OTWAY llegó para hacerse cargo del cuidado ambiental mientras que los pescadores fueron excluidos durante un año de actividades de turismo debido al daño que estaban produciendo con las crías. Los pescadores en ese momento comenzaron a ver cómo un agente externo llegaba a la caleta con una visión de patrimonio sobre el recurso, fue cuando aprendieron sobre el cuidado de los pingüinos, pero al mismo tiempo comenzaron a reprobar que la Fundación -cuya mentalidad debía ser de cuidado ambiental sin fines de lucro- empezara a cobrar y obtener beneficios económicos con la excusa de la conservación. "Se instaló acá para cuidar el ecosistema y no hizo nada, puro turismo, ponía doce personas por bote y le cobraba cinco mil [pesos] por pasajero y había gente que además dejaba su aporte" ${ }^{19}$. Finalmente, la Fundación abandonó el sector haciéndose cargo la Corporación Nacional Forestal (CONAF) hasta la actualidad. Las prácticas del buceo traídas por los pescadores del norte, en la medida en que hacían uso de los islotes, alternaron con nuevas prácticas de turismo en verano.

En sus inicios el AMERB fue impulsado con dificultades por uno de los pescadores nortinos. El proceso de adjudicación del área fue solicitado además por otra organización, debido a que no había residencias estables en el lugar. Como estrategia de organización, los pescadores del norte, observando su debilidad para lograr ser beneficiados por ser en su mayoría afuerinos, decidieron integrar un número importante de miembros chilotes. Así es como se permitió la entrada al Sindicato de personas que no realizan actividades de pesca. La estrategia dio resultado y el Sindicato del lugar denominado "Viento Fuerte" obtuvo los derechos del área.

Esta área de manejo la sacó adelante un hombre que era del norte (...). Lo positivo del área es que permite invertir harto billete en algo, lo negativo es que mucha gente está en el área de manejo y no vive del $\operatorname{mar}^{20}$.

Actualmente, las actividades de turismo, pesca de mar abierto y buceo en el AMERB la comparten dos grupos dentro del lugar, aquellos que manifiestan su interés por obtener recursos del turismo de pingüineras y aquellos que se encuentran conformes con las actividades de pesca y buceo. Mientras que el primer grupo, por medio de organizaciones transitorias, manifiesta encuentros y desencuentros en torno a la administración del turismo en las pingüineras, el segundo desde sus inicios manifiesta una actitud permisiva respecto de personas que vienen de afuera a trabajar en el lugar. Aunque en los últimos años ha habido conflictos con algunos pescadores que han intentado instalarse en el sector, la permisividad a la entrada y salida es predominante y se presenta como una dificultad para la estabilidad de las organizaciones que administran los recursos naturales. Al interior del Sindicato, junto a los buzos antiguos hay miembros que sin ser buzos hacen uso de su derecho al área pagando las cuotas y subcontratando a otros buzos experimentados para que realicen las labores que les corresponden como miembros. Estos últimos no ven, como el primer grupo, a la caleta como un futuro eje de desarrollo basado en el turismo. Más bien consideran el AMERB como una inversión cuyo beneficio es independiente de la comunidad que vive de ellos y cuyo beneficio es posible de obtener, desde la ciudad, sin vivir en el sector.

En Puñihuil las actividades agrícolas fueron quedando excluidas desde el inicio de la llegada de pescadores durante la fiebre del loco. El nomadismo de éstos pescadores hizo de Puñihuil, en primera instancia, un puerto de base desde donde explorar al sur y al norte de Chiloé. Estas trayectorias continúan aún en la actualidad. Los pescadores realizan sus viajes por el sur hasta las costas de Cucao y por el norte hasta el Canal de Chacao en busca de cardúmenes, replicando una movilidad dentro de la Isla, que nació en sus viajes iniciales desde Los Vilos hacia el sur de Chile. La pesca se ha integrado con las prácticas de buceo. En los viajes, los pescadores llevan redes y también los equipos de buceo. Sus experiencias en este territorio heterogéneo y con problemas de organización, muestran que aún 
cuando hay procesos de cambio y aprendizaje en las prácticas y saberes, es de mayor importancia el factor de pertenencia territorial, como eje central en el tipo de apropiación de los recursos.

\section{Prácticas, Saberes y Tiempos en las Caletas de Guabún y Puñihuil}

Los cambios de estaciones durante el año son factores importantes para el funcionamiento de los sistemas productivos, lo que en su conjunto ha hecho emerger un verdadero calendario socio-geolitoral de prácticas productivas diferenciado en estas dos sociedades litorales. En el caso de Puñihuil la situación productiva durante el invierno es casi nula. En algunas ocasiones, durante el invierno los pescadores viajan por uno o dos días al sector e intentan pescar, bucear y cuidar sus botes, sin embargo, la jornada casi siempre es pasajera debido al mal tiempo. La llegada del verano condiciona el funcionamiento productivo del lugar generando no sólo la afluencia de miles de turistas sino además la instalación de carpas, ranchas y la construcción de nuevos lugares. En Puñihuil existen dos polígonos que demarcan las AMERB (Figura 1), entre ellas se encuentran los tres islotes donde anidan las colonias de pingüinos. En la misma figura, hacia los bordes costeros, se observan los asentamientos de pescadores y los asentamientos de turismo. Un tercer espacio lo constituye el espacio de mar comprendido entre el sector de Cucao y el Canal de Chacao, espacio que constituye el maritorio apropiado a través de las prácticas de pesca demersal y bentónica de los pescadores de Puñihuil.

La pesca demersal presenta flexibilidad en los grados de dedicación, lo cual les permite a los pescadores alternarla con prácticas de buceo, logrando así una maximización de actividades dentro de la variabilidad meteorológica. Estando en sus ranchas (Figura 1), los pescadores dedican tiempo a la convivencia y al arreglo de instrumentos, manteniendo una constante vigilancia de las condiciones meteorológicas a partir de diversas fuentes de información. Los pescadores de Puñihuil identifican dos tipos de situación del mar: cuando el mar está "picado" que es un mar con oleajes interiores densos producto del viento que sopla en contra de las olas, y cuando el mar está "calmo" que es un mar sin mayores vaivenes. Cuando el mar está calmo se dedican a bucear, mientras que cuando está picado se dedican a pescar.
Las alternancias de la pesca y el buceo en una misma jornada se producen cuando hay mar calmo. Primero se calan las redes en diversos sectores y durante el tiempo de espera-que puede durar días-, se realizan labores de buceo en sectores lejanos donde no hay AMERB. Para calar las redes se ponen en práctica formas de identificación local, como los pájaros que vuelan sobre cardúmenes para alimentarse de los peces, también los pescadores buscan sectores con mayor cantidad de microalgas y krill, a través de la identificación de sectores donde rondan ballenas. "Tenemos paradas de quince redes, y hacemos cuarenta paradas" 21 , luego, "lo dejas todo el día calado y queda toda la noche, al otro día se va a las seis de la mañana a levantar, y así se va corriendo y con un GPS se van marcando las coordenadas" 22 . Mientras las redes están caladas, los pescadores alistan el compresor, las mangueras, sus trajes y quiñes ${ }^{23}$.

Este sistema de decisiones pauteadas, bastante flexibles en la práctica, ha permitido al pescador mantener constantemente un proceso de elaboración de planes de acción sobre lo que se hará durante el día o los siguientes días. Los movimientos de los pescadores están asociados en primera instancia al movimiento o estacionalidad de los cardúmenes y la identificación de sectores libres para bucear; junto a lo anterior, a las condiciones inmediatas de vientos, corrientes y los cambios en la biodisponibilidad de recursos, juegan un rol importante para que en su conjunto se configure un territorio de pesca particular. Al mismo tiempo, y producto de la creciente escasez de recursos, el territorio de pesca particular se amplía: "antes íbamos más cerca... cada vez vamos alejándonos más"24.

Con una considerable menor movilidad espacial, entre los medios campo-mar, el habitante de Guabún -por su parte- va desarrollando sus saberes y prácticas. En el sector hay diversas playas identificadas y nombradas por sus habitantes (Figura 1); hacia las colinas, el suelo se utiliza para situar los hogares, sembrar papas y mantener animales. Los hogares poseen invernaderos abonados con algas donde se cosechan hortalizas y verduras destinadas al consumo familiar. En una de las quince playas identificadas, se ubica el AMERB, razón por la cual han construido un galpón para reuniones y guardar botes. Cada pescador tiene su propio bote y lo utiliza junto a su esposa en alguna playa del sector. Las mujeres trabajan como asistentes y también como buzos. Cuando se debe trabajar en el AMERB, ya 
sea para limpieza ${ }^{25}$ o bien para cosechar, los botes se trasladan a la playa Los Chonos y luego de días de trabajo vuelven a sus hogares y playas. En el pasado, este movimiento de traslado de botes se realizó en un sector mucho más amplio debiendo hacerlo por medio de tractores. Ahora, cada cual mantiene un espacio definido y reducido que alterna el área de manejo con el lugar de trabajo usualmente utilizado.

El ambiente campo-mar propio de esta caleta implica una gama de actividades productivas que hacen diversa la cotidianeidad del territorio y permiten mayor grado de coordinación con el medio costero. En Guabún se denomina recolección de orilla a la actividad que consiste en recoger los recursos depositados en las playas, y marisqueo a la actividad que consiste en extraer recursos que crecen en las rocas o permanecen depositados en aguas levemente profundas. En el AMERB se extrae el recurso loco (Concholepas concholepas) mediante el buceo, mientras que en las playas locales se extrae erizo (Loxechinus albus), lapa (Fissurella spp.), cangrejo (Taliepus dentatus), jaiba (Ovalipes trimaculatus), pepino (Athyonidium chilensis), chaperines (Fisurella spp.), luga (Gigartina skottsbergii), llapín (Nothogenia afastigiata) y cochayuyo (Durvillaea antarctica) mediante la práctica de marisqueo. Esta práctica es realizada por hombres cuando se trata de un marisqueo en mar profundo y por mujeres cuando es entre rocas de menor profundidad. Las producciones se destinan al consumo familiar y a la venta en la feria de Ancud. La actividad de recolección de orilla se enfoca en la luga (Gigartina skottsbergii), y es casi exclusiva de las mujeres, algunas de las cuales se acompañan de sus hijos para realizar la actividad durante el verano. Últimamente, su producción se destina al comercio a intermediarios que acopian cantidades mayores para vender a empresas exportadoras.

La alternancia en los tiempos de prácticas dentro de la cotidianeidad aparece entre labores de recolección, marisqueo, trabajos del campo para los

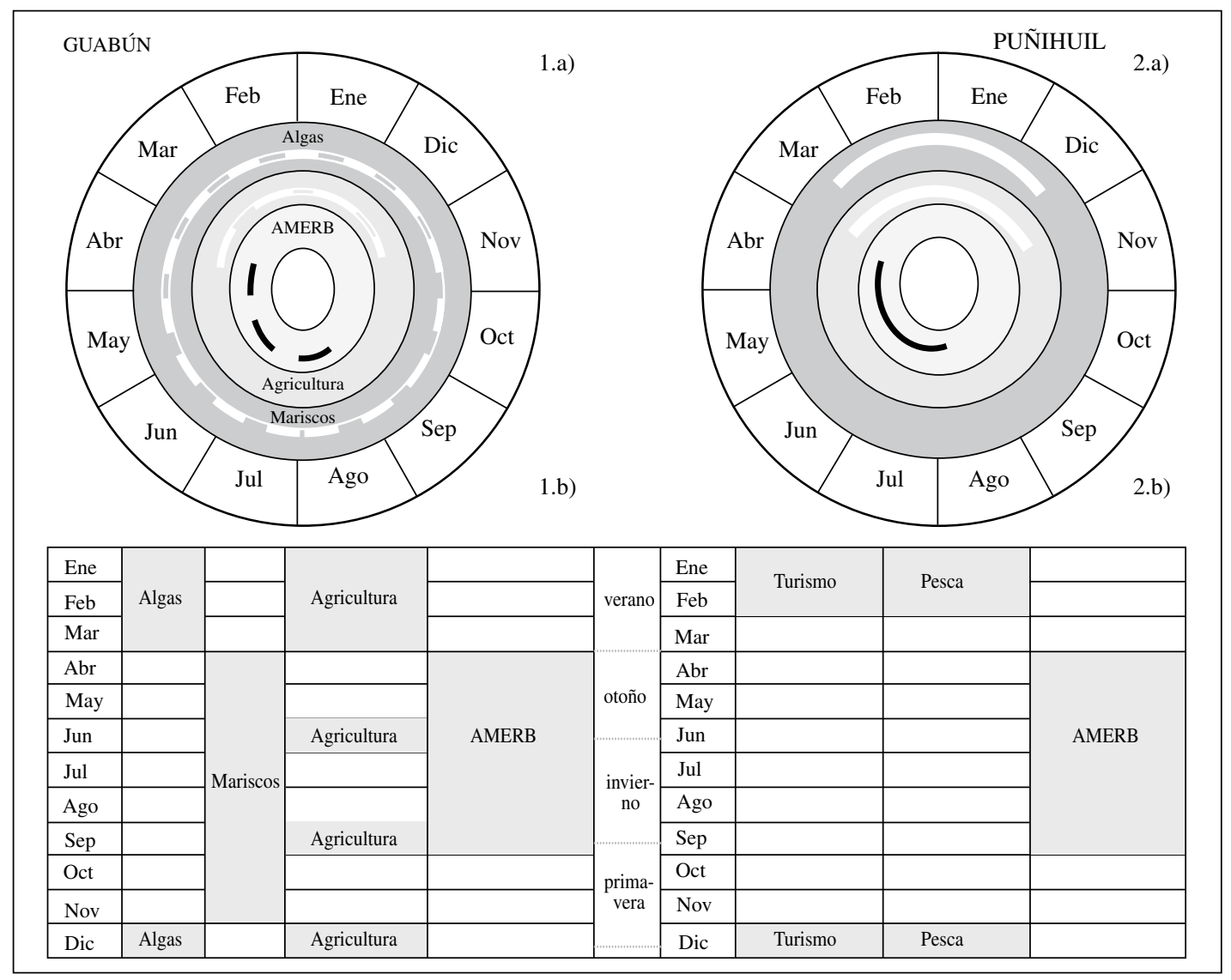

Figura 2. Calendarios socio-geolitoral de prácticas productivas en Guabún y Puñihuil, Chiloé.

Socio-geo-littoral calendars of productive practices in Guabún and Puñihuil, Chiloé. 
hombres y trabajos del hogar y las huertas para las mujeres. Debido a que cuando baja la marea queda una mayor cantidad de recursos en la playa, la práctica de recolección de orilla se realiza de manera coordinada con los momentos en que esto ocurre, es decir, cambiando su tiempo de ocurrencia una hora más tarde al transcurrir cada día ${ }^{26}$. Ello define una primera coordinación. Después de saber si hay buen tiempo y a qué hora estará la marea baja, se va a la playa a extraer el recurso. En el lugar, el alga se toma con las manos y cada montón se deposita en un cuadrado de terreno ubicado en la arena para que el sol seque el recurso. Cada cierto tiempo dan vuelta las algas para que seque por el otro lado. Si se hace tarde "se deja sacado y juntado, cuando se ve que va a llover, se deja tapado con nalca (Gunnera tinctoria)" $^{\text {"27. }}$. Los pescadores salen a sus territorios a bucear durante la mañana y en la tarde se dedican a actividades de cultivo del pasto para animales y cosecha de papas, alternando diversas y cambiantes ocupaciones en el hogar. Por su parte las mujeres, durante el tiempo de secado de la luga (Gigartina skottsbergii), se dedican a actividades de huerta o a otras actividades de marisqueo de orilla, pudiendo viajar a sus hogares y luego volver a buscar el alga seca unas horas más tarde.

Comparativamente, y durante el transcurso de un año, los tiempos de las prácticas observadas en Guabún difieren de aquellos observados en Puñihuil (Figura 2). En efecto, es posible observar que la conjunción de prácticas de campo y mar permite a los habitantes de Guabún tener continuidad productiva durante el año (Figura 2.2a). Mientras que en Puñihuil, el período de invierno se observa sin ocupación (Figura 2.2b). Con ello se demuestra que el arraigo territorial de Guabún genera una apropiación diversa de los recursos (Figura 2.1a). En Puñihuil el desarraigo termina generando una falta de apropiación y utilización del entorno, lo cual se refuerza con una lógica de búsqueda y explotación del recurso con independencia de la conformación de un modo de vida litoral (Figura 2.1b). El arraigo de Guabún y desarraigo de Puñihuil tienen un impacto en el uso de las AMERB.

\section{Apropiación Sociocultural del Litoral en Guabún y Puñihuil}

Aunque han llegado desde el norte a instalarse en Chiloé, los pescadores de Puñihuil también demuestran apropiaciones simbólicas, por ejemplo, al nombrar objetos y especialmente dar nombre a algunos lugares del sector, como "la piedra del oso" 28 también integrada al circuito turístico de las pingüineras. La denominación de estos geosímbo$\operatorname{los}^{29}$ trata de equiparar el hecho de que en lugares cercanos y en toda la isla, se da lugar la mitología chilota. Cercano a las pingüineras existe la "Piedra Run”, en cuya cara superior habría una olla de oro; esta piedra es llamada así por los chilotes debido al sonido que emiten las olas al pasar bajo sus cuevas inferiores similar al sonido de un Run-Run ${ }^{30}$. Es una denominación propia de chilotes que los pescadores del norte han equiparado con su propia "piedra del oso" y otros lugares nombrados recientemente por ellos. Estas construcciones simbólicas manifiestan su asociación con factores territoriales y ejemplifican la dinámica cotidiana de apropiación cultural sobre las geografías litorales.

La diversidad interna en Puñihuil se manifiesta en un imaginario del turismo, que atrae las aspiraciones tanto de pescadores como de pequeños inversionistas a través del beneficio económico que brindan las pingüineras. Dicho imaginario coexiste con otro imaginario nómade, que rememorando aquel período cercano a 1980 con la apertura de recursos y la ausencia de normativas y pautas de extracción, no ha cotejado la realidad actual, en lo que significa la disminución de los recursos y precios respecto a dicha "época de oro". Recurriendo a diversas estrategias, los pescadores que portan este imaginario intentan mantener presente dicha época, recurriendo a la comercialización informal para la continuidad de cantidades y precios, y un interés por seguir reproduciendo aquel tiempo pretérito en la actualidad del territorio.

A partir de la coexistencia de estos imaginarios, las prácticas se debaten en un espacio costero socialmente fragmentado. El espacio del turismo se toma el lado izquierdo de la playa y el sector de ranchas y pesca artesanal (Figura 1), está confinado a un sector que, desde el punto de vista del turismo predominante, intenta ser poco visible. En medio de la playa se conforma una pared imaginaria que divide los estilos de vida que paradójicamente se han mostrado como complementarios. En efecto, los pescadores nortinos han permitido la emergencia de microempresarios del turismo en la caleta y, sin embargo, no han permitido que una fundación conservacionista se instale en el sector. Al mismo tiempo permiten la llegada de nuevos agentes de turismo y ponen trabas para que nuevos pescadores 
provenientes del norte lleguen a instalarse. Ambos imaginarios se orientan mutuamente a seguir la idea común de cuidar un lejano lugar que debe ser mantenido en la lejanía de otros actores. Esto explica la extraña situación que se da entre los pescadores del norte, que realizan lejanos viajes a otros sectores en busca de recurso y además utilizan el AMERB, pero son permisivos a que el turismo sea, a modo de fachada, la imagen predominante de la caleta cuando ésta se proyecta al mundo.

En el habitante de Guabún, por su parte, coexisten elementos del imaginario del campesino, que desde su lógica terrestre utiliza y protege los recursos del mar y el imaginario del nuevo pescador, que instruyendo una diferenciación respecto al interés depredador del pescador del norte, ha ido exacerbando dicha oposición, transformando imperceptiblemente su intención en un sentido de defensa la apropiación de recursos económicos. La comunidad de pescadores de Guabún comparte entre ellos las mismas prácticas sin compartir necesariamente el sentido dado a ellas en la dimensión socioproductiva. En Guabún el arraigo territorial producido en el tiempo ha volcado una diversidad de denominaciones sobre el espacio (Figura 1) que le permite a la comunidad vivir en un ambiente amplio y con suficiente biodiversidad; el AMERB se conecta con el mercado internacional mientras que las otras playas se conectan con el mercado local y la economía familiar sin predominar una sobre las demás. Para el pescador de Guabún, los pescadores del norte del país han llegado al sur porque en el norte depredaron sus recursos. En base a ello el pescador de Guabún ha escogido una forma de administrar los recursos que implica no abrir completamente la caleta hacia el mercado y mantener la territorialidad a favor de la comunidad.

\section{Discusión}

\section{Hacia las estrategias de lo diverso en los asen- tamientos costeros}

La concepción oficial de las caletas enmarca sus límites en la zona terrestre y costera que cubre el asentamiento humano, y define la caleta artesanal como centro de desembarque (Montoya 2002). Sin embargo, al considerar la dimensión cotidiana y concreta, la caleta artesanal incluye una diversidad de actividades que quedan excluidas de los escenarios de desarrollo para la pesca artesanal.
En cuanto al manejo de recursos, la apropiación sociocultural resulta ser la base desde la cual las figuras de administración pesquero-artesanal pueden tener mayor o menor éxito en su implementación y desarrollo. En este ámbito queremos destacar que al revelar las experiencias de Guabún y Puñihuil hemos observado que ninguna de las dos caletas ha puesto su futuro en la seguridad que brindaría el AMERB. Lo cual entrega una cualidad suficiente para entender la aplicación de estas políticas como un complemento cuya orientación puede potenciar la apropiación diversa del territorio o bien puede especializar una apropiación económica de él.

Las estrategias de desarrollo pueden vincular de manera efectiva aquellos puntos en común entre las diversidades de los asentamientos. Las conexiones y el interés de las comunidades en participar de procesos de desarrollo se originan a partir de las diferentes apropiaciones socioculturales del litoral, estando sus potencialidades de desarrollo en directa relación con la complejidad territorial existente y que ha venido siendo -si no resultado, al menos- expresión de las múltiples variables que entran en juego y en buena medida se anclan a la experiencia de habitar el territorio. Desde las prácticas surge entonces la posibilidad de que dichas estrategias consideren la complejidad territorial de cada asentamiento y se integren en las estrategias de complementariedad, generadas desde las condiciones locales de cada asentamiento de pescadores.

En los asentamientos estudiados existen también otras posibilidades de desarrollo endógeno. Conocemos el caso en que los pescadores artesanales -a partir de sus percepciones- construyen un interesante mapa del fondo marino de las AMERB. Desde sus experiencias como buzos, conocen a niveles específicos las diferencias entre especies en una roca u otra. De hecho, revisan constantemente la distribución de las especies en las rocas del fondo marino. También distinguen las relaciones de alimentación entre especies e incluso realizan prácticas para alimentar los recursos que cultivan en las AMERB. Se hace necesario potenciar estrategias que incluyan este tipo de conocimientos, se requieren estudios sobre el conocimiento ecológico local del fondo marino, lo cual estimamos contribuiría tanto a la diversificación de las AMERB como también enriquecería el conocimiento preciso sobre los fondos marinos, sus usos y dinámicas.

En específico, en Guabún las condiciones están dadas para entender su sistema como un sistema 
socioecológico vinculado, en el sentido que lo define Fikret Berkes (2008:447). Estos procesos de aprendizaje y adaptación por parte de pescadores y el sentido dado al contexto social de defensa de los recursos condicionan positivamente cambios en la cotidianeidad al tiempo que posibilita procesos de diferenciación territorial en playas y sectores aledaños. Se trata de un sistema complejo adaptado a la geografía y orientado naturalmente a una incipiente administración local de los recursos. Estas características son potencialidades para el manejo local; especialmente en Guabún las observamos como acciones de gestión colectiva del ambiente que precisamente $-\mathrm{y}$ en concordancia con Ostrom et al.- incluyen a "la pesca, el consenso de normas que prevengan la entrada de más personas a un área específica, apoyo mutuo en épocas de siembra y cosecha forestal o agrícola (Ostrom et al. citado en Cunningham 2007).

La administración pesquero-artesanal en Guabún puede ser considerada así como un sistema de manejo a pequeña escala, con unidades de manejo con tiempos propios de extracción y de reproducción. Al respecto, la escala de observación del pescador puede ser entendida en dos niveles: (1) La escala particular de los bancos y caladeros históricos; (2) La escala de las zonas de pesca que cubren con sus trayectos de trabajo en el mar. De manera que los límites territoriales de los asentamientos de pescadores rebasan en mucho tanto el encuadre terrestre de las caletas artesanales como los límites que proyectan las geometrías que delimitan el fondo marino.

Potenciar dicha articulación es importante, por ejemplo, para la soberanía alimentaria de las comunidades y sus respuestas frente a cambios climáticos, culturales y económicos en el futuro. Esto es posible ya que muchas de estas comunidades mantienen tradiciones de solidaridad como la minga, que son condiciones favorables para la administración local de recursos costeros (Ostrom 2000). Es importante entonces descubrir las inteligencias locales (Saavedra 2008) y creatividades de los asentamientos de pescadores y desde allí no sólo evidenciar sino potenciar las alternativas de desarrollo territorial de la pesca artesanal.

\section{Conclusiones}

La experiencia internacional muestra crecientemente la importancia que la pesca artesanal tiene para la conservación y el manejo de recursos. En este sentido, los saberes y prácticas se muestran como una posibilidad de articulación que tiende hacia el diseño de posibles estrategias de desarrollo territorial en los asentamientos; y que al mismo tiempo genere un manejo local de recursos costeros. Los territorios costeros estudiados en Chiloé, garantes aún de una gran biodiversidad, demuestran la existencia de comunidades que se han vinculado de distinto modo al litoral. Las continuidades y discontinuidades en sus temporalidades tienden hacia apropiaciones acordes al manejo sustentable de recursos o bien sólo consideran los recursos como un bien económico transable en el mercado. Dicha conducta frente a los recursos naturales está en estrecha relación con el arraigo territorial y la temporalidad del asentamiento.

Las diversidades internas de los asentamientos remiten a las características socioculturales de sus habitantes o usuarios, confluyendo o divergiendo en distintas direcciones condicionadas por la organización de pescadores hacia el mejor o peor uso de las figuras de administración pesquero-artesanales. Las prácticas asociadas a dichas diversidades manifiestan tiempos locales que en el caso de haber un mayor arraigo territorial generan una diversidad de actividades que cubre el año calendario e integra el AMERB de manera no especializada, asimilando un uso complementario de ella. En aquella caleta donde los tiempos productivos se concentran únicamente en el verano, la asimilación de la figura de manejo se torna dificultosa, lo que en su conjunto se refleja y redunda -al mismo tiempo- en falta de arraigo territorial y la consecuente sobrecarga del sistema en cortas temporadas durante el año. En los casos estudiados, las diversidades internas convergen hacia apropiaciones socioculturales con características de diversidad productiva (Guabún) y también hacia la maximización económica (Puñihuil).

La memoria práctica, entendida como reservorio de experiencias entre actores y con el medio ambiente, se presenta como un ámbito a destacar en la elaboración de estrategias de desarrollo territorial y manejo de recursos pesquero-artesanales.

Agradecimientos: Los resultados son producto del Proyecto FONDECYT 1080665: "Las sociedades litorales como sistemas de prácticas y saberes tradicionales y científicos: la caleta como modelo de imaginarios pesqueros y dinámicas de uso y apropiación de recursos marinos". Agradecemos 
a Mauricio Ceballos por la elaboración del mapa y a James Park por la traducción de los títulos de las figuras. Agradecemos también a los evaluadores y evaluadoras por sus dedicadas revisiones y comentarios. Finalmente, agradecemos la buena disposición de los pescadores y pescadoras de Guabún y Puñihuil quienes, en medio de sus labores cotidianas, nos hablaron abiertamente de sus vidas, mostrándonos sus modos de vivir y habitar el litoral chilote.

\section{Referencias Citadas}

Alcalá, G. 1999. Con el Agua hasta los Aparejos: Pescadores y Pesquerías en el Soconusco. Centro de Investigaciones y Estudios Superiores en Antropología Social, Chiapas.

- - - 2003. Políticas Pesqueras en México: 1946-2000. Contradicciones y Aciertos en la Planificación de la Pesca Nacional. Colegio de México. Centro de Investigación Científica y de Educación Superior de Ensenada: El Colegio de Michoacán, México.

Andrade, B., F. Arenas y R. Guijón 2008. Revisión crítica del marco institucional y legal chileno de ordenamiento territorial: el caso de la zona costera. Revista de Geografía Norte Grande 41:23-48.

Andriguetto-Filho, J.M. 1999. Sistemas Técnicos de Pesca e suas Dinâmicas de Transformação no Litoral do Paraná, Brasil. Tesis Doctoral, Universidade Federal do Paraná, Curitiba.

Artal, O., N. Almonacid y A. Sepúlveda 2009. Vórtices atmosféricos en islas chilenas. Ciencia Ahora 23:37-42.

Avalos, P. 2006. Los Impactos Socioespaciales en las Caletas de Pescadores Artesanales de la Comuna de Corral en el Marco de la Legislación Pesquera Promulgada entre los Años 1990-2005. Memoria para optar al título profesional de Geógrafo, Escuela de Geografía, Universidad de Chile, Santiago.

Baliero, W., E. Biasco, D. Conde, R. Cortazzo, M. Fossati, D. Gorfinkiel, E. Lorenzo, R. Menafra, C. Píriz e I. Roche. 2006. Estudio de Base sobre el Estado del Manejo Costero Integrado en Uruguay: práctica, capacitación e investigación. Proyecto Sustentabilidad de la Zona Costera Uruguaya (AUCCCIDA). Universidad de la República, Montevideo/Dalhousie University.

Barragán, J.M., C. Alvarado y C. Castro 2005. Hacia la Gestión Integrada de las Zonas Costeras en Chile. En La Gestión de Áreas Litorales en España y Latinoamérica, editado por J.M. Barragán Muñoz, pp. 109-136. Universidad de Cádiz, Cadiz.

Berkes, F. 2008. La pesquería de pequeña escala: alternativa al manejo convencional de recursos. En El Manejo de las Pesquerías en Ríos Tropicales de Sudamérica, editado por D. Pinedo y C. Soria, pp. 443-459. Mayol Ediciones, Bogotá.

- - - 2004. Rethinking Community-based Conservation. Conservation Biology 18:621-630.

- - - 1999. Sacred Ecology. Traditional Ecological Knowledge and Management Systems. Taylor Francis, London.

Berkes, F. y C. Folke 1997. Linking Social and Ecological Systems. Cambridge University Press, Cambridge.

Berkes, F. y N. Turner 2005. Conocimiento, aprendizaje y la flexibilidad de los sistemas socioecológicos. Gaceta Ecológica 77:5-17.
Bitrán, E. 1989. Proposición de un régimen de administración de las pesquerías chilenas. Ambiente y Desarrollo 5:71-87.

Calfucura, E. y E. Figueroa 2005. Valoración económica de los recursos marinos en Chile: Usos y conservación de la biodiversidad. En Biodiversidad Marina: Valoración, Usos y Perspectivas, editado por E. Figueroa, pp. 235-282. Editorial Universitaria, Santiago.

Camus, P. 2001. Biogeografía marina de Chile continental. Revista Chilena de Historia Natural 74:587-617.

Camus, P. y E. Hajek 1998. Historia Ambiental de Chile. Andros Impresores, Santiago.

Carlsson, L. y F. Berkes 2005. Co-management: Concepts and methodological implications. Journal of Environmental Management 75:65-76.

Castro, C. y C. Alvarado 2009. La Gestión del Litoral Chileno: Un Diagnóstico. CYTED, Ciencia y Tecnología para el Desarrollo, IBERMAR, Red Iberoamericana.

Ceballos, M. 2009. Análisis de la Ocupación Territorial y Manejo de Algas en las Caletas de Guabún y Pupelde Incorporando los Saberes Tradicionales. Comuna de Ancud, Región de Los Lagos. Memoria para optar al Título de Geógrafo, Escuela de Geografía, Universidad de Chile, Santiago.

Cereceda, P. 2000. Los atrapanieblas, tecnología alternativa para el desarrollo rural. Revista Medioambiente y Desarrollo 16:51-56.

Cox, M.I. 2007. Plan Integral de Conservación y Desarrollo, Zona Sur de la Cordillera de Piuchén, Chiloé: Una Propuesta de Desarrollo Participativo. Tesis para optar al título de Antropólogo y al Grado de Licenciado en Antropología, Escuela de Antropología, Universidad Austral de Chile, Valdivia.

Cunningham, E. 2007. Gestión de los recursos locales en comunidades indígenas de costa caribe de Nicaragua: Potencialidades y dilemas de la gestión costera. Cuaderno de Investigación Nitlapan $\mathrm{N}^{\circ} 29$, Managua.

Diegues, A.C. 2005. El mito moderno de la naturaleza intocada. Recuperado el 17 de marzo de 2010, de http://www.rema.org. py/documentos/El\%20mito\%20de\%201a\%20naturaleza $\% 20$ intocada.pdf.

Egaña, G. 2008. Identidades Territoriales como Estrategias de Adaptación Cultural a la Ecología del Estuario ChoroyTraiguén, Provincia de Osorno. Memoria para optar al título de Antropólogo Social, Departamento de Antropología, Universidad de Chile, Santiago.

FAO 2006. Consulta de expertos sobre los procesos de regulación del acceso a la pesca y la sostenibilidad de las pesquerías en pequeña escala en América Latina. 
Fariña, J., P. Ossa y J. C. Castilla 2008. Ecosistemas marinos. En Biodiversidad en Chile. Patrimonio y Desafíos, CONAMA, pp. 96-105. Ocho Libros Editores, Santiago.

Floriani, N. 2007. Evaluación de Tierras por Agricultores Ecológicos de Río Blanco del Sur: Un Abordaje GeoSocio-Agronómico del Paisaje Rural. Tesis de Doctorado Interdisciplinario en Medioambiente y Desarrollo, Universidad Federal de Paraná, Curitiba.

Freire, J. 2001. Pesca y ecosistemas marinos. Alternativas viables a la gestión insostenible de las pesquerías. El Ecologista 46-50.

García-Allut, A. 1999. Compartición del conocimiento tradicional y científico para una gestión más adecuada de las pesquerías. Etnográfica 3:109-331.

- - - 2003. La pesca artesanal, el cambio y la patrimonialización del conocimiento. PH: Boletín del Instituto Andaluz del Patrimonio Histórico 44:74-83.

García-Reyes, V. y N. Martí-Sanz 2007. Etnoecología: punto de encuentro entre naturaleza y cultura. Revista Ecosistemas $16: 45-54$.

Giménez, G. 2001. Cultura, territorio y migraciones. Aproximaciones teóricas. Alteridades 11:5-14.

Hucke-Gaete, R. 2004. Distribución, Preferencia de Hábitat y Dinámica Espacial de la Ballena Azul en Chile. Tesis Doctoral, Escuela de Graduados, Universidad Austral de Chile, Valdivia.

Jaramillo, E., R. de la Huz, C. Duarte y H. Contreras 2006. Depósitos de algas varadas y artrópodos macrofaunales en playas de arena de la costa de Chile. Revista Chilena de Historia Natural 79:337-351.

Johannes, R. 1993. Integrating traditional ecological knowledge and management with environmental impact assessment. En Traditional Ecological Knowledge Concepts and Cases, editado por J. Inglis, pp. 33-39. International Program on Traditional Ecological Knowledge, Ottawa.

McGoodwin, J. 2002. Comprender las culturas de las comunidades pesqueras. Clave para la ordenación pesquera y la seguridad alimentaria. Documento Técnico de Pesca $\mathrm{N}^{\circ}$ 401, FAO, Roma.

Marín, W. 2007. Caleta Los Bronces, Cambio de una Cultura Competitiva Extractiva a una Sustentable Asociativa. Tesis para obtener el grado de Magíster en Antropología y Desarrollo, Departamento de Antropología, Universidad de Chile, Santiago.

Montoya, M. 2002. Clasificación de Caletas Pesqueras Artesanales. Recuperado el 20 de junio de 2009, de Subsecretaría de Pesca: www.subpesca.cl/mostrararchivo.. spp $\mathrm{id}=661$.
Morales, H.L. 1986. La modernización de las pesquerías chilenas. Impactos sociales y ecológicos. Ambiente y Desarrollo 2:33-46.

Morán-Angulo, R., J. Téllez-López y J. Cifuentes-Lemus 2010. La investigación pesquera: una reflexión epistemológica. Revista THEOMAI. Estudios sobre Sociedad y Desarrollo 21:97-112.

Pomeroy, R. y F. Berkes 1997. Two to tango: The role of Government in fisheries Co-management. Marine Policy 21:465-480.

Quintanilla, V. 2004. Degradación del bosque pluvial en una cuenca hidrográfica del norte de la Isla Grande de Chiloé. Revista de Geografía Norte Grande 31:73-84.

Rebouças, G., A. Filardi y P. Vieira 2006. Gestión integrada y participativa de la pesca artesanal: potencialidades y obstáculos en el litoral de Santa Catarina. Ambiente y Sociedad 9: 83-104.

Ross, J. y J. Banuchi 2007. Conocimiento Ecológico Tradicional (CET) de los Pescadores del Área Noroeste de Puerto Rico: Correlaciones entre Especies y Hábitat en el Entorno Marino. Centro Interdisciplinario de Estudios del Litoral. Universidad de Puerto Rico en Mayagüez.

Sáez, C. 2006. Efectos geográficos de Eventos Catastróficos. Caso Terremoto-Maremoto 22 de mayo de 1960, Ancud. Memoria para optar al título profesional de Geógrafo, Escuela de Geografía, Universidad de Chile, Santiago.

Schneider, W., R. Fuenzalida, R. Núñez, J. Garcés-Vargas, L. Bravo y D. Figueroa 2007. Discusión del sistema de la corriente de Humboldt y masas de agua en la zona norte y centro de Chile. Revista Ciencia y Tecnología del Mar 30:21-36.

SERNAPESCA 2009. Subsector Pesquero Artesanal. Recuperado el 09 de marzo de 2011, de Servicio Nacional de Pesca: www. sernapesca.cl.

Ther Ríos, F. 2008. Prácticas cotidianas e imaginarios en sociedades litorales. El sector de Cucao, Isla Grande de Chiloé. Chungara Revista de Antropología Chilena 40:67-80.

Valderrama, J. 2009. Situación de las Figuras de Administración Pesquera sobre los Territorios Costeros en Chile. Sustentabilidady Dinámicas Socioculturales en tres Caletas de la Comuna de Ancud, X Región. Memoria para optar al título profesional de Geógrafo, Escuela de Geografía, Universidad de Chile, Santiago.

Vargas, C. 2005. Gente de Mar: de Pescadores Depredadores a Cultivadores de Esperanzas. Tesis para optar al grado de licenciado en Historia, Departamento de Ciencias Históricas, Universidad de Chile, Santiago.

Zuleta, A. 1990. ¿Cómo expandir los límites? Ambiente y Desarrollo 6:66-71.

\section{Notas}

1 Este trabajo es resultado del Proyecto FONDECYT 1080665 "Las sociedades litorales como sistemas de prácticas y saberes tradicionales y científicos: la caleta como modelo de imaginarios pesqueros y dinámicas de uso y apropiación de recursos marinos".
2 En general se ha utilizado el término conocimiento ecológico tradicional cuando se refiere a los saberes y prácticas de culturas indígenas y conocimiento ecológico local cuando no lo son. La definición utilizada con mayor frecuencia corresponde a Berkes (1999), quien la define como "cuerpo acumulativo de conocimientos, prácticas y creencias que 
evoluciona a través de procesos adaptativos y es comunicado por transmisión cultural durante generaciones, acerca de la relación de los seres vivos, incluidos los seres humanos, de uno con el otro y con su medio ambiente".

3 Ejemplo de ello es la "Fiebre del Loco" y el "Boom de la Merluza" en donde los pescadores se trasladan desde el norte hacia el sur buscando la mayor abundancia del recurso. Estos desplazamientos continúan hasta la actualidad desplazándose cada vez más al sur.

4 Las Áreas de Manejo y Explotación de Recursos Bentónicos (AMERB) son un ejemplo, no necesariamente bueno en todos los casos, donde el ámbito territorial se encuentra ligado al ámbito de manejo de recursos. Las organizaciones de pescadores tienen la custodia exclusiva de estas áreas y pueden tomar decisiones sobre las cantidades de extracción de los recursos que allí existan. Sin embargo, producto del desconocimiento de las territorialidades propias de los pescadores artesanales, estas figuras legales de administración han desencadenado peleas entre organizaciones por la defensa de sus áreas.

5 Esta Región posee una gran importancia para el sector pesquero-artesanal. Trabajan 45.583 pescadores artesanales (SERNAPESCA 2009), que constituyen el $60 \%$ de pescadores registrados en el país, lo que equivale al mayor número de pescadores por región.

6 Guabún se ubica en el borde costero noroccidental de la isla aproximadamente a la altura de los $41^{\circ} 48^{\prime} 36^{\prime \prime}$, a 8 millas $(13 \mathrm{~km})$ al norte de Puñihuil. Mientras que esta última se ubica en el borde costero occidental de la isla aproximadamente en los $41^{\circ} 55^{\prime} 44^{\prime \prime} \mathrm{S}$, a 8 millas (13 km) al sur de Guabún.

7 El área de manejo de Guabún se ubica entres los siguientes

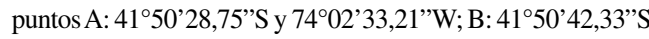
y $74^{\circ} 02^{\prime} 38,14^{\prime \prime}$ 'W C: $41^{\circ} 50^{\prime} 54,76^{\prime \prime}$ ' y $74^{\circ} 01^{\prime} 57,86^{\prime \prime}$; D: $41^{\circ} 51^{\prime} 03,27^{\prime \prime}$ ' y $74^{\circ} 01^{\prime} 49,29$ 'W; E: $41^{\circ} 50$ ' $57,55^{\prime \prime}$ 'S y 7401'42,86”'W; contando con una extensión aproximada de 63 hectáreas. Esta AMERB data desde el año 2001 mediante el decreto exento $\mathrm{N}^{\circ} 601$. El comportamiento el 2007 fue de 190.000 unidades de locos $(50.000 \mathrm{~kg}$ ), el 2008 se aprobaron 160.000 unidades $(48.000 \mathrm{~kg})$ y lo extraído fue 140.000 , el 2009 se aprobaron 120.000 unidades y se extrajeron 110.000 aprox. El 2010 se extrajeron 15.000 unidades (4.500 kg aprox.). El precio por Kilógramo se ordena por calibre, desde el calibre más pequeño por unidad 3.500 pesos $/ \mathrm{kg}$, hasta el calibre mayor 7.000 pesos/kg (año 2009). El año 2010 se aprobó su $6^{\circ}$ informe de seguimiento. Por su parte, en Puñihuil el AMERB se divide en dos sectores el primero se ubica entre los puntos A: $41^{\circ} 55^{\prime} 26,75^{\prime \prime}$ 'S y $74^{\circ} 01^{\prime} 42,11^{\prime \prime} \mathrm{W}$; B: $41^{\circ} 54^{\prime} 58,70^{\prime \prime} \mathrm{S}$ y $74^{\circ} 01^{\prime} 42,11^{\prime \prime} \mathrm{W}$; C: $41^{\circ} 54^{\prime} 58,70^{\prime \prime} \mathrm{S}$ y $74^{\circ} 00^{\prime} 22,90^{\prime \prime} \mathrm{W}$; D: $41^{\circ} 55^{\prime} 17,83^{\prime \prime} \mathrm{S}$ y $74^{\circ} 00^{\prime} 22,90^{\prime \prime} \mathrm{W}$, el segundo se ubica entre los puntos A $41^{\circ} 56^{\prime} 34,05^{\prime \prime}$ 'S y $74^{\circ} 02^{\prime} 07,55^{\prime \prime} \mathrm{W}$; B $41^{\circ} 56^{\prime} 27,24^{\prime \prime}$ ' y $74^{\circ} 03$ ' $19,63^{\prime \prime} \mathrm{W}$; C $41^{\circ} 55^{\prime} 31,47^{\prime \prime} \mathrm{S}$ y $74^{\circ} 03$ '33,38'W; D $41^{\circ} 55^{\prime} 23,15^{\prime \prime}$ 'S y $74^{\circ} 03$ '23,70”W; E $41^{\circ} 55^{\prime} 30,00^{\prime \prime} 74^{\circ} 02^{\prime} 34,47^{\prime \prime}$, y datan del 2002 mediante el decreto $\mathrm{N}^{\circ} 966$, contando con una extensión aproximada de 328 hectáreas. Para el 2008 se extrajeron 350.000 aprox., para el 2009 se aprobaron 431.000 aprox. Durante el 2009 el precio fue de 3.200 pesos $/ \mathrm{kg}$. En el año 2010 el primer sector (A) aprobó su $6^{\circ}$ informe de seguimiento y el sector $\mathrm{B}$ su $7^{\circ}$.
8 Juan Aedo, funcionario público agrega "Incluso el habitante de Guabún sabe perfectamente lo que está pasando afuera, pero se queda tranquilo, porque saben donde están parados".

9 Don Claudio Vargas y don Pedro Pino. Don Claudio Vargas, en Osorno, a punto de alistarse para formar parte del ejército que viaja a Chiloé y conoce a la señora Hilda, hija de las familias antiguas de Guabún. Ellos se conocen, se casan y posteriormente se trasladan a vivir a Guabún, en donde comienzan una vida de esfuerzo condicionada por la poca aceptación que don Claudio tuvo para la familia de la chilota. Don Pedro Pino, en aquel tiempo trabajador obrero en la empresa FIAT, participó activamente en el sindicato y fue despedido tras el golpe militar. En su intento de alejarse de Santiago, viaja al sur de Chile donde conoce a una habitante de Guabún. Poco a poco da un vuelco a su vida y se transforma en un habitante de Guabún.

10 Miguel Burgos.

11 La "fiebre del loco" es un período derivado del neoliberalismo que al abrir la captura de este recurso permitió su compra por los mercados extranjeros. El elevado precio y la gran demanda internacional por el recurso produjo una serie de movilizaciones de pescadores hacia el sur del país y diversos fenómenos socioculturales tales como la emergencia de mercados locales móviles o en embarcaciones, campamentos espontáneos, poblamientos permanentes, monedas de cambio y circuitos de comercio, prostitución, mercados informales y costumbres que aún existen como la venta ilegal de este recurso. El período ha quedado testimoniado en el cine nacional en la película del mismo nombre.

12 Miguel Burgos, habitante de Guabún.

13 Claudio Vargas, Entrevista 18/02/09.

14 El Boom de las algas es un período similar a la fiebre del loco donde principalmente el mercado asiático produjo una gran demanda por el pelillo (Gracilaria spp.), debido a su derivado Agar, sustancia gelatinosa utilizada para el cultivo de microorganismos y la composición de diversas sustancias en la industria alimentaria.

15 Pedro Pino, Entrevista 27/02/09.

16 Por medio del equipo de investigación, los pescadores de Guabún se han puesto en contacto con pescadores de la Caleta El Manzano portadores de saberes de pesca con espineles abocados a la merluza (Merluccius australis). Este proceso de cruce de saberes se encuentra en un estado de iniciación y está siendo monitoreado por el equipo de trabajo.

17 Eduardo Leiva Tapia, Entrevista 02/02/09.

18 Juan Carlos Soto, Entrevista 07/02/09.

19 Juan Carlos Soto, Entrevista 07/02/09.

20 Ibíd.

21 Juan Carlos Soto, Entrevista 07/02/09.

22 Cristian Gutiérrez, Entrevista 10/02/09.

23 Quiñe es una herramienta utilizada para el buceo. Consiste en un aro metálico el cual posee una bolsa de red conectada a sus bordes. Los recursos entran por la argolla metálica y luego son descargados al desatar la bolsa de red por su extremo inferior.

24 Juan Carlos Soto, Entrevista 07/02/09. La constante búsqueda de recursos y los cambios técnicos han acompañado la ampliación del territorio de pesca que se ha desplazado desde un sector al norte de la caleta, a la altura de Guabún 
(41 $\left.48^{\prime} 36^{\prime \prime S}\right)$, hacia sectores al sur de ella, a la altura de la Isla Metalqui (42॰11'44”S).

25 La limpieza consiste extraer del área la estrella de mar debido a que es un depredador natural del loco (Concholepas concholepas).

26 La primera hora de salida un día X corresponde aproximadamente a las seis de la mañana, de manera que en el día $\mathrm{x}+1$ la más baja marea será a las siete de la mañana, en el día $\mathrm{X}+2$ será a las ocho, así en el día $\mathrm{X}+\mathrm{N}$ será a las $6+\mathrm{N}$ hrs, donde $\mathrm{N}=1,2,3 \ldots 14$.

27 Se denomina nalca (Gunnera tinctoria) a la hoja de la planta, usada para alimentación en la parte de sus tallos y sus hojas para cocinar los curantos chilotes. Miryam, entrevista 25/05/09.

28 La piedra del oso, se ubica frente a la caleta de Puñihuil (Figura 1), los pescadores han nombrado así a esta piedra por la forma de oso que tiene. Durante los viajes de los turistas a las pingüineras, los pescadores muestran esta piedra como una parte del paisaje con valor turístico. Intentan con ello manifestar una apropiación de aquel lugar que están mostrando como guías.

29 Los geosímbolos son definidos como "un lugar, un itinerario, una extensión o un accidente geográfico que por razones políticas, religiosas o culturales reviste a los ojos de ciertos pueblos o grupos sociales una dimensión simbólica que alimenta y conforta su identidad" (Bonnemaison en Giménez 2001).

30 Juego popular latinoamericano cuya construcción consiste en hacer pasar las dos puntas de una cuerda por dos agujeros hechos en alguna tapa metálica o por los agujeros de un botón y luego unir los extremos de la cuerda de modo que las dos vías de la cuerda traspasan el botón y forman un circuito mediante un nudo sencillo. 
